\title{
Mechanism of $\varepsilon$-caprolactone polymerization in the presence of alkali metal salts: investigation of initiation course and determination of polymers structure by MALDI-TOF mass spectrometry
}

\section{Zbigniew Grobelny $^{1}$ (D) Sylwia Golba ${ }^{2}$ Justyna Jurek-Suliga ${ }^{2}$}

Received: 15 February 2018 / Revised: 21 September 2018 / Accepted: 6 October 2018 /

Published online: 13 October 2018

(c) The Author(s) 2018

\begin{abstract}
Various alkali metal salts were applied as initiators for $\varepsilon$-caprolactone anionic ringopening polymerization in tetrahydrofuran at room temperature. It was observed that potassium methoxide $(\mathrm{MeOK})$, potassium isopropoxide $(i$-PrOK) and potassium tert-butoxide $(t$-BuOK) nonactivated or activated by 18-crown-6 (18C6) initiated polymerization mainly by deprotonation of the monomer. In the case of potassium hydride $(\mathrm{KH})$, its basicity increased with the ability of the ligand for cation complexation. For example, $\mathrm{KH}$ without ligand or with weak ligands for $\mathrm{K}^{+}$as $12 \mathrm{C} 4$ reacted exclusively by ring opening. However, in the presence of strong ligands, as $15 \mathrm{C} 5,18 \mathrm{C} 6$ or cryptand $\mathrm{C} 222$, basicity of $\mathrm{H}^{-}$increased with the ability of the ligand for cation complexation. In the last case, $32 \%$ of the monomer was deprotonated. In these systems, gaseous $\mathrm{H}_{2}$ evolved during the initiation. Deprotonation of the monomer by some initiators resulted in macromolecules with reactive aldehyde group or lactone ring as starting groups. They took part in the reaction with potassium alkoxide active centers of growing chains leading to the formation of branched poly $(\varepsilon$-caprolactone)s. Sodium hydride $(\mathrm{NaH})$ was inactive, but in the presence of 15 -crown-5 or 18 -crown- 6 initiated polymerization exclusively by ring opening. MALDI-TOF mass spectrometry supported with ${ }^{13} \mathrm{C}$ NMR and SEC was used for analysis of the polymers obtained. Mechanism of the studied processes was proposed and discussed.
\end{abstract}

Keywords Anionic polymerization $\cdot \varepsilon$-Caprolactone $\cdot$ Alkali metal salts $\cdot$ MALDITOF mass spectrometry

Zbigniew Grobelny

zbigniew.grobelny@us.edu.pl

1 Institute of Chemistry, University of Silesia, 40-007 Katowice, Poland

2 Institute of Materials Science, University of Silesia, 40-007 Katowice, Poland 


\section{Introduction}

Poly( $\varepsilon$-caprolactone) (PCL) is an important polymer due to its mechanical properties, miscibility with other polymers and biodegradability [1]. It is produced by polycondensation of 6-hydroxyhexanoic acid or ring-opening polymerization (ROP) of $\varepsilon$-caprolactone ( $\varepsilon$-CL). PCL has been used in different fields, i.e., in tissue engineering [2, 3], in drug delivery systems [4, 5], in microelectronics [6] or in packaging [7]. $\varepsilon$-Caprolactone polymerizes by ring opening according to four mechanisms, i.e., anionic [8], cationic [9], monomer-activated ROP [10] and coordination-insertion ROP [8-10]. PCL is a semicrystalline polymer having a low glass transition temperature and melting point [11]. Much more interesting are block copolymers that have excellent physical properties and belong to the most important materials used in technological applications. Some examples involve poly(CL-b-styrene) block copolymers [12] or poly(MMA-b-CL) triarm block copolymers synthesized by the simultaneous ATPR and ROP in one step [13]. Copolymers including PEG and PCL unit are good transporter for hydrophobic drugs delivery [14]. Recently, the synthesis of poly(CL-b-EG-b-CL) ABAtype block copolymers has been performed by "click" chemistry method [15]. Another type of copolymers' architecture is graft one where copolymers have a branching chain structure attaching polymer units to another polymer backbone [16]. By synthesis of a novel macroinitiator (RAFT-ROP agent), poly[CL-bEPCH-CL-(g- $n$-BMA)] block-graft copolymers were prepared [17].

The present paper is dedicated to anionic ROP of $\varepsilon$-CL. It was known that this lactone does not polymerize with carboxylate anions, even with crowned cations [18]. It is in accordance with the general inability of these anions to react with esters. The only exception are esters with a good leaving group. The strained ring like in $\beta$-propiolactone ( $\beta$-PL) or $\beta$-butyrolactone $(\beta$-BL) can be considered as an equivalent of a good leaving group. However, the application of $\mathrm{NaH}$ for $\varepsilon$-CL polymerization causes acyl-oxygen bond cleavage during initiation [19]. Recently [20], macrocyclic ligands activated by alkali metal hydroxides, i.e., $\mathrm{LiOH}, \mathrm{NaOH}$ and $\mathrm{KOH}$, have been used successfully for $\varepsilon$-CL polymerization. In all systems, initiation proceeded by acyl-oxygen bond cleavage. In the polymerization mediated with $\mathrm{KOH}$-activated strong complexing ligands, i.e., 15-crown-5 (15C5) or 18-crown-6 (18C6), linear and cyclic polymers were formed.

Anionic polymerization of $\varepsilon$-CL can be also easily induced by alkoxides and the growing species are alkoxide anions. In the presence of potassium alkoxides, $\varepsilon$-CL ring opens exclusively in the acyl-oxygen position [21]. Dale et al. [22] proposed that during the initiation step $t$-BuOK adds to carbonyl group of the monomer. Next, the ring opening occurs, resulting in the formation of $t$-butyl ester with alkoxide group, which initiates the polymerization. However, recently Penczek et al. [18] suggested that anions with high basicity and low nucleophilicity due to steric hindrance, e.g., $t$-BuOK, could initiate polymerization of $\varepsilon$-CL by proton abstraction mostly with reversible manner. Stable potassium enolate is expected as a product of this reaction; however, its role in the polymerization was not determined. 
The aim of the present work was reinvestigation of the mechanism of $\varepsilon$-CL polymerization initiated with potassium alkoxides. Three of them were chosen for the study, i.e., $\mathrm{MeOK}, i$-PrOK and $t$-BuOK. Comparatively, polymerizations were also carried out in the presence of several other salts, namely $\mathrm{NaH}, \mathrm{KH}, \mathrm{Ph}_{2} \mathrm{PK}$, $\mathrm{Ph}_{3} \mathrm{CK}, \mathrm{Ph}_{3} \mathrm{HBK}$ and $\mathrm{CbK}$ (carbazylpotassium). Macrocyclic ligands, i.e., 12C4, 15C5, 18C6, DCH24C8 and C222, were applied as cation complexing agents. All processes were carried out in tetrahydrofuran solution at room temperature. MALDITOF and ${ }^{13} \mathrm{C}$ NMR techniques were used for the determination of the structure of polymers prepared. Molar masses and dispersity of polymers were obtained by SEC chromatography.

\section{Experimental}

\section{Materials}

$\varepsilon$-Caprolactone (Aldrich) was heated over $\mathrm{CaH}_{2}$ for $24 \mathrm{~h}$ at room temperature and then distilled under reduced pressure in argon atmosphere prior use. Anhydrous tetrahydrofuran (THF) (Acros Organics) was kept over $\mathrm{CaH}_{2}$ and distilled at $66{ }^{\circ} \mathrm{C}$. Potassium hydride $(\mathrm{KH})$ was purified according to the procedure described by Brown [23]. A $35 \mathrm{wt} \%$ dispersion of $\mathrm{KH}$ in mineral oil (Aldrich) was mixed with $n$-pentane in a dry argon atmosphere and then decanted. It was repeated three times followed by a threefold washing with dry THF. Finally, the solvent was evaporated in vacuum. Methanol, isopropanol, carbazole, $\mathrm{NaH}, \mathrm{Ph}_{2} \mathrm{PK}, \mathrm{Ph}_{3} \mathrm{HBK}, \mathrm{Ph}_{3} \mathrm{CH}$, $t$-BuOK (the last as $1.0 \mathrm{M}$ solution in THF), 12C4, 15C5, 18C6, DCH24C8 and C222 (from Aldrich) were used without purification.

\section{Initiators syntheses and lactone polymerization}

$\mathrm{MeOK}, i$-PrOK, $\mathrm{CbK}$ and $\mathrm{Ph}_{3} \mathrm{CK}$ were synthesized in the reaction of appropriate substrate with $\mathrm{KH}$-activated $18 \mathrm{C} 6$ in THF solution at $20^{\circ} \mathrm{C}$ [24]. All syntheses were carried out in a $50 \mathrm{~cm}^{3}$ reactor equipped with a magnetic stirrer and a Teflon valve enabling substrates delivery and sampling under argon atmosphere. During the reactions gaseous hydrogen was evolved. For example, KH (0.08 g, $2.0 \mathrm{mmol}), 18 \mathrm{C} 6$ $(0.53 \mathrm{~g}, 2.0 \mathrm{mmol})$ and THF $\left(15.0 \mathrm{~cm}^{3}\right)$ were introduced into the reactor and then methanol $(0.064 \mathrm{~g}, 2.0 \mathrm{mmol})$ was added by the use of microsyringe. The reaction mixture was then stirred for $1 \mathrm{~h}$ until all $\mathrm{H}_{2}\left(44.7 \mathrm{~cm}^{3}\right)$ was evolved. This resulted in a fine dispersion of pure anhydrous potassium methoxide in the ether medium. That system was used as the initiator when $\varepsilon$-caprolactone $(4.56 \mathrm{~g}, 40 \mathrm{mmol})$ was introduced into the reactor. Thus, the initial concentration of the monomer was $2.0 \mathrm{~mol} /$ $\mathrm{dm}^{3}$ and monomer/initiator molar ratio was $20 / 1$. The reaction mixture was then stirred for several hours. After complete conversion of the monomer, methyl iodide $\left(0.5 \mathrm{~cm}^{3}, 8.0 \mathrm{mmol}\right)$ was added to it as a quenching agent. After the separation of potassium iodide-crown complex precipitate from the system by filtration, THF was evaporated from the solution in vacuum at $50{ }^{\circ} \mathrm{C}$, yielding white solid polymer. 
In all polymerizations, the concentration of the monomer during the process was monitored by SEC technique. The final conversion was $\sim 99 \%$ after few minutes to 2 weeks. The yields of the reactions were 96-98\%. Some of the processes were heterogeneous (e.g., initiated $\mathrm{KH}$ - or $\mathrm{NaH}$-activated 12C4), others were homogeneous (e.g., in the presence of potassium alkoxides).

\section{Measurements}

$100 \mathrm{MHz},{ }^{13} \mathrm{C}$ NMR spectra were recorded in $\mathrm{CDCl}_{3}$ at $25{ }^{\circ} \mathrm{C}$ on a Bruker Avance 400 pulsed spectrometer equipped with 5-mm broadband probe and applying Waltz16 decoupling sequence. Chemical shifts were referenced to tetramethylsilane serving as an internal standard. To obtain a good spectrum of the polymer main chain exhibiting its microstructural details, about 3000 scans were satisfactory, but in order to observe the signals of the polymer chain ends more than 10,000 scans were necessary. Molar masses and dispersities of polymers were obtained by means of size exclusion chromatography (SEC) on a Shimadzu Prominence UFLC instrument at $40{ }^{\circ} \mathrm{C}$ on a Shodex $300 \mathrm{~mm} \times 8 \mathrm{~mm}$ OHpac column using tetrahydrofuran as a solvent. Polystyrenes were used as calibration standards. Matrix-assisted laser desorption/ionization-time of flight (MALDI-TOF) spectra were recorded on a Shimadzu AXIMA Performance instrument with dithranol used as a matrix.

\section{Results and discussion}

\section{Polymerization of $\varepsilon$-caprolactone initiated with potassium alkoxides}

Potassium alkoxides, i.e., MeOK, $i$-PrOK and $t$-BuOK, were used for initiation of $\varepsilon$-CL polymerization. Analysis of the polymers obtained by ${ }^{13} \mathrm{C}$ NMR gave information about final groups, present in the polymer chains after treating with MeI as quenching agent. Further data concerning polymer chemical structure were obtained by the use of MALDI-TOF technique. Figure 1 shows, for example, MALDI-TOF spectrum of the polymer prepared in the presence of $t$-BuOK.

Three main series of signals are observed in the spectrum. The series of very weak peaks, i.e., from $\mathrm{m} / \mathrm{z} 889.1$ to $\mathrm{m} / \mathrm{z} 1800.5$, represents macromolecules with $t$-butoxy starting groups and methoxy end groups. They form adducts with hydrogen ion. For example, the peaks at $\mathrm{m} / \mathrm{z} 889.1,1117.3$ and 1459.9 represent macromolecules A with 7, 9 and $12 \varepsilon$-caprolactone units $\left(M_{\text {calc }}=888.1,1116.4\right.$ and 1458.8), respectively. These macromolecules form in the polymerization initiated with $t$-BuOK according to the reaction presented in Scheme 1.

${ }^{13} \mathrm{C}$ NMR analysis of the polymer reveals strong signals characteristic for carbons derived from polymers of $\varepsilon$-CL. They are following signals, which correspond well with the literature data [25]: $\delta$ (in ppm): 24.6, 25.6, 28.4, 34.1, $64.2\left(\mathrm{OCO}\left(\mathrm{CH}_{2}\right)_{5}\right)$, 173.5 (OO). Moreover, Fig. 2 shows weak signal of $\left(\mathrm{CH}_{3}\right)_{3} \mathrm{CO}-$ starting group (at $28.1 \mathrm{ppm}$ ) and signal of $-\mathrm{OCH}_{3}$ end group (at $63.0 \mathrm{ppm}$ ). 


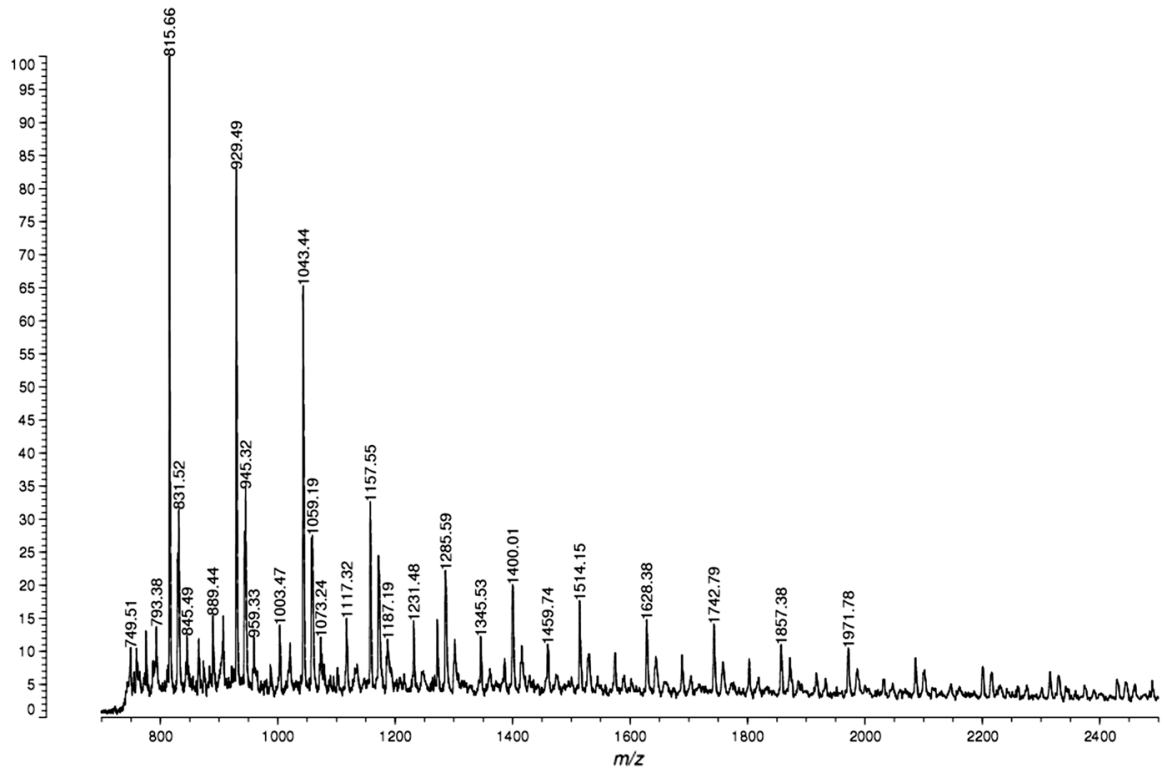

Fig. 1 MALDI-TOF spectrum of poly( $\varepsilon$-CL) prepared by the use of $t$-BuOK and quenched by MeI
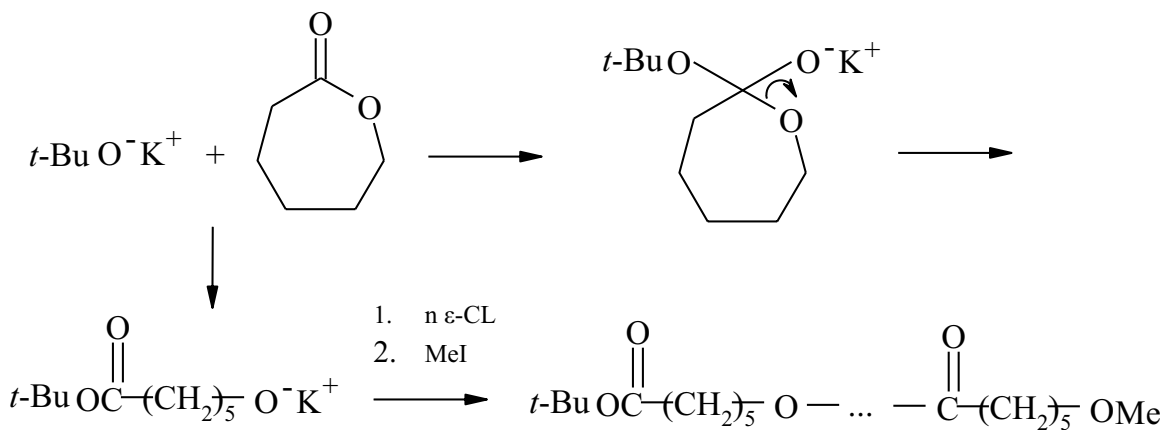
1

$\mathbf{A}$

Scheme 1 Anionic polymerization of $\varepsilon$-CL initiated with $t$-BuOK by ring opening of the monomer (side reaction)

Then, it was proposed that the main series of signals in Fig. 1, i.e., from $\mathrm{m} / \mathrm{z}$ 815.7 to $\mathrm{m} / \mathrm{z}$ 1271.6, represents macromolecules without $t$-butoxy starting group, which form in the polymerization initiated with organopotassium compound 2 resulting from deprotonation of the monomer with initiator (Scheme 2). For example, the peaks at $\mathrm{m} / \mathrm{z}$ 815.7, 1043.4 and 1271.6 represent macromolecules B with 7, 9 and 11 lactone units $\left(M_{\text {calc }}=814.0,1042.3\right.$ and 1270.6), respectively, and one methoxy end group. They form adducts with hydrogen ion. 
Fig. 2 Carbon signals of $\left(\mathrm{CH}_{3}\right)_{3} \mathrm{CO}-$ and $-\mathrm{OCH}_{3}$ terminal groups in ${ }^{13} \mathrm{C}$ NMR poly $(\varepsilon-\mathrm{CL})$ obtained with $t$-BuOK and quenched by MeI

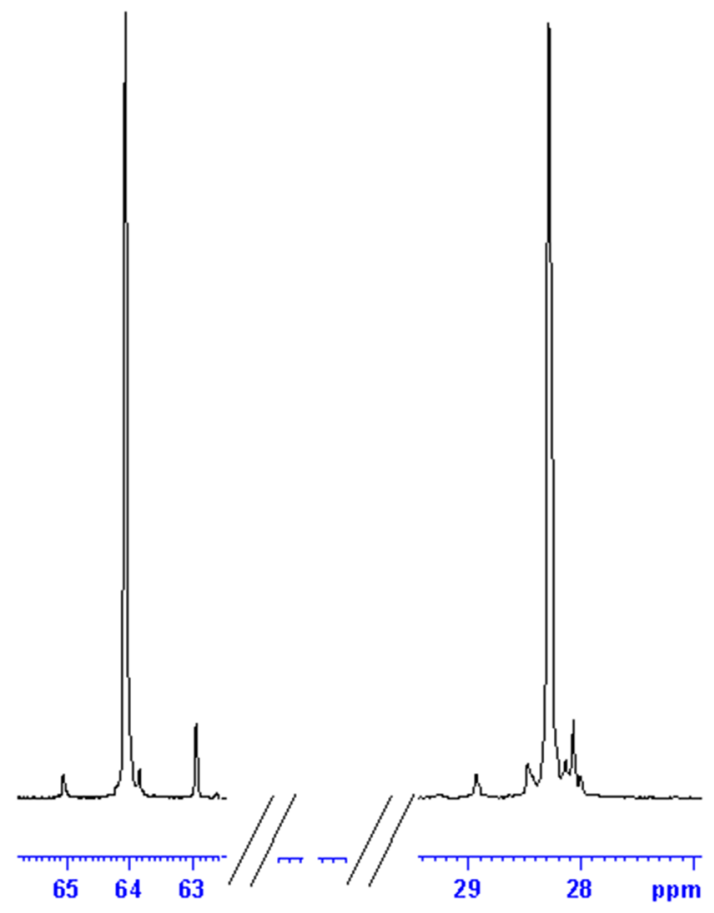

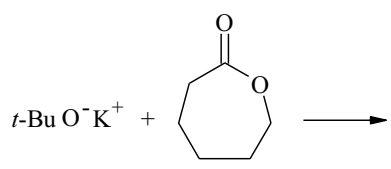

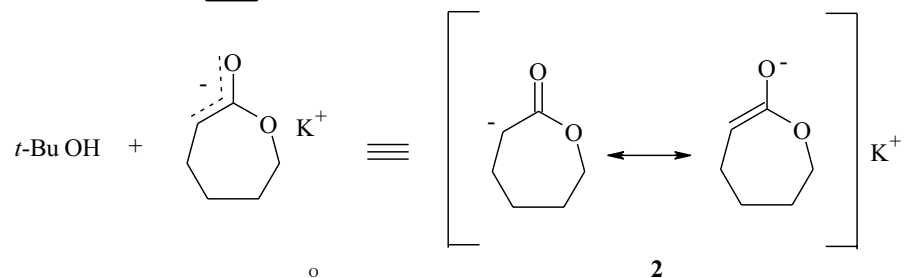

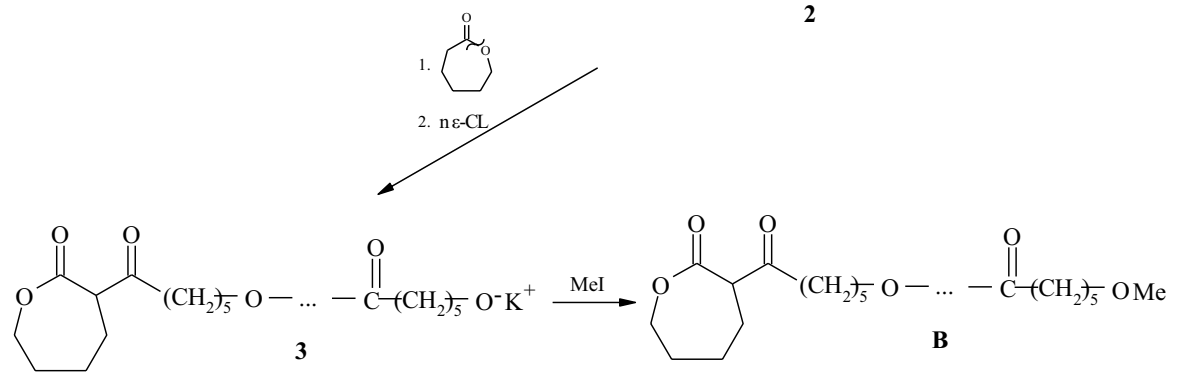

Scheme 2 Anionic polymerization of $\varepsilon$-CL initiated with $t$-BuOK by deprotonation of the monomer 
Third series of signals was observed in the spectrum at $m / z$ 831.5-1971.8. For example, the peaks at $\mathrm{m} / \mathrm{z} 831.5,1400.0$ and 1857.4 represent branched macromolecules with 7, 12 and 16 monomer units $\left(M_{\text {calc }}=828.0,1398.0\right.$ and 1855.0), respectively, and two methoxy end groups, which form proton adducts. It was proposed that macromolecules 3 react mutually due to the presence of lactone ring, which can open by acyl-oxygen bond cleavage in the reaction with alkoxide end group. Macromolecules $\mathbf{C}$ with three arms form in the process (Scheme 3).

Series of signals derived from macromolecules $\mathbf{A}$ and $\mathbf{B}$ were absent in the spectrum of poly $(\varepsilon-\mathrm{CL})$ prepared in the presence of $t$-BuOK activated by $18 \mathrm{C} 6$. Signals of macromolecules $\mathbf{C}$ were observed in the spectrum, as well as new series of signals at $m / z$ 845.7-2803.3 (Fig. 3).

For example, the peaks at $\mathrm{m} / \mathrm{z} 845.8,1758.3$ and 2445.6 represent more branched macromolecules with 7,15 and 21 monomer units $\left(M_{\text {calc }}=842.0\right.$, 1755.0 and 2439.9), respectively, and three methoxy end groups which form<smiles>[Z7]OCC(=O)CC(=O)COCCCCC(=O)C1CCCCOC1=O</smiles>

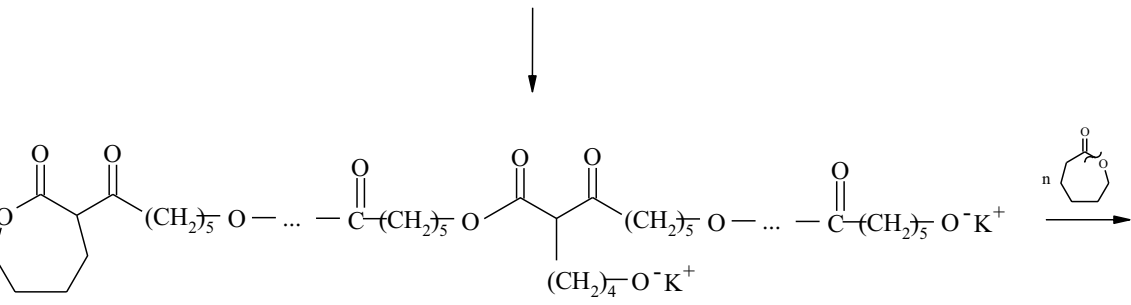

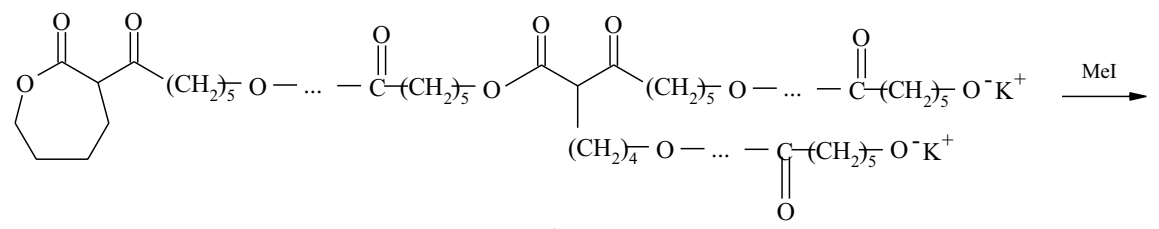

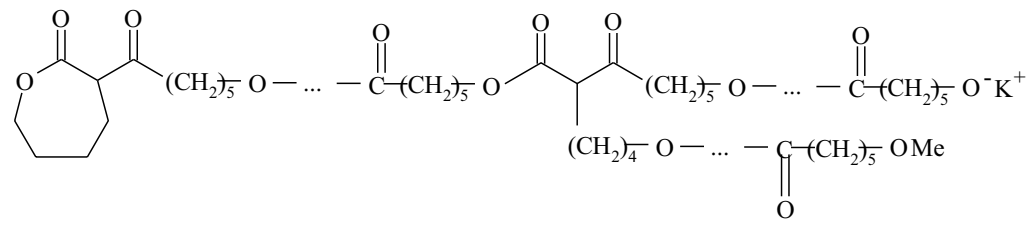

C

Scheme 3 Intermolecular reaction of two macromolecules $\mathbf{3}$ and further polymerization leading to macromolecules $\mathbf{C}$ with three arms 


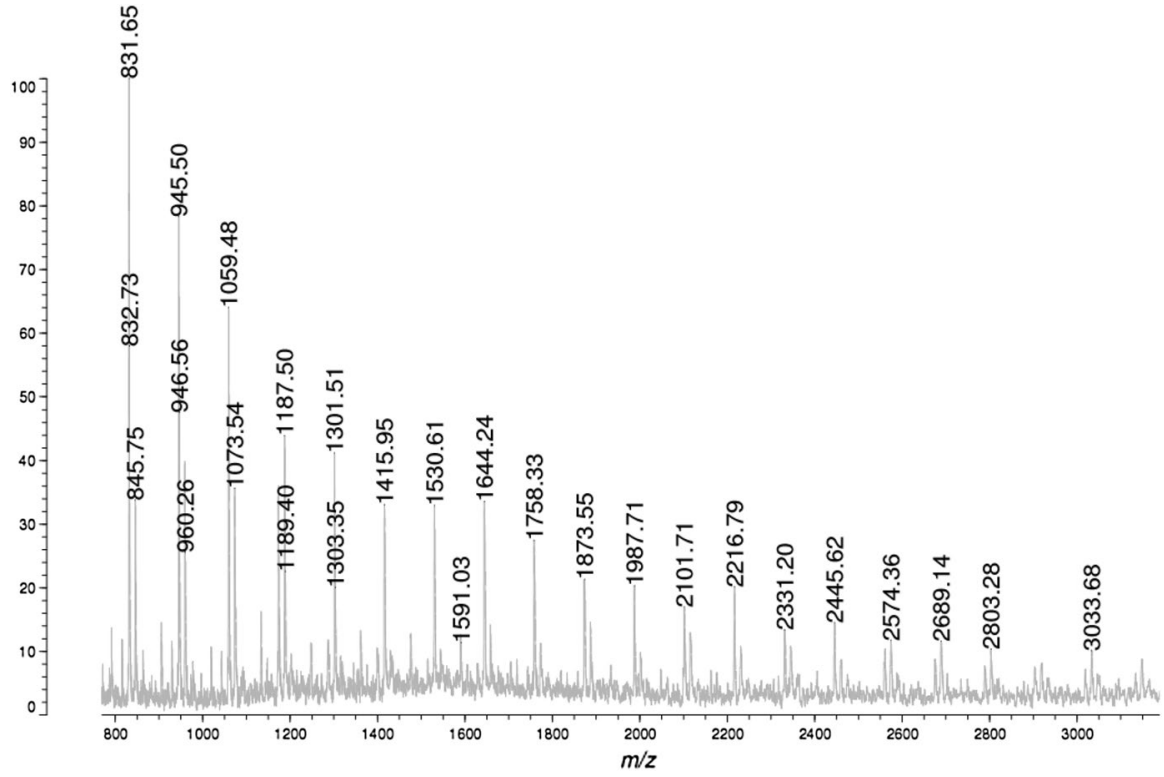

Fig. 3 MALDI-TOF spectrum of poly( $\varepsilon$-CL) synthesized in the presence of $t-\mathrm{BuO}^{-} \mathrm{K}^{+}$and quenched by MeI

adducts with hydrogen ion. Thus, we proposed that macromolecules $\mathbf{3}$ can also react with 4 giving branched macromolecules $\mathbf{D}$ (Scheme 4).

It is also worth noting that cyclic oligomers were not found in all studied systems. Similar phenomenon was observed in the polymerization initiated with other potassium alkoxides. However, in ${ }^{13} \mathrm{C}$ NMR spectrum of the polymer prepared with the presence of $\mathrm{MeOK}$ weak signal of $\mathrm{CH}_{3} \mathrm{OCO}-$ starting group (at $51.4 \mathrm{ppm}$ ) was shown (Fig. 4). It results from acyl-oxygen bond cleavage by initiator in this case.

Table 1 presents molar masses and dispersities of prepared polyesters. The ring-opening/deprotonation ratio values were calculated by comparison of intensities of the MALDI signals of peculiar macromolecules structure along with confirmation based on the ${ }^{13} \mathrm{C}$ NMR data. Such protocol is proper as the chosen

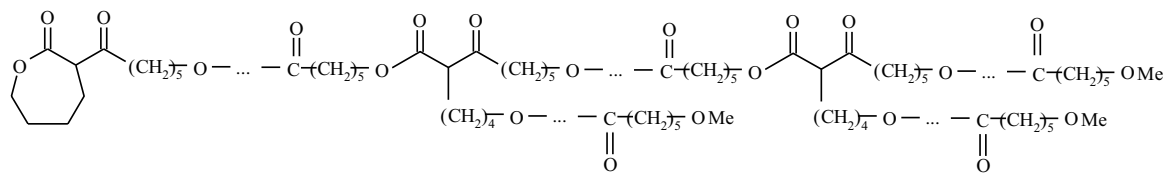

D

Scheme 4 Branched macromolecules D formed in the reaction of macromolecules 3 with 4 (after methylation) 
Fig. 4 Carbon signal of $\mathrm{CH}_{3} \mathrm{OCO}$ - starting group in ${ }^{13} \mathrm{C}$

NMR spectrum of poly $(\varepsilon-\mathrm{CL})$

obtained with $\mathrm{MeOK}$ and

quenched by MeI

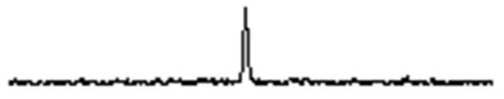

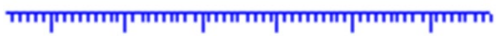

$\begin{array}{llllll}54 & 53 & 52 & 51 & 50 & \mathrm{ppm}\end{array}$

Table 1 Polymerization of $\varepsilon$-CL initiated with potassium alkoxides at $20^{\circ} \mathrm{C}$

\begin{tabular}{llllll}
\hline No. & Initiating system & Mechanism of initiation & Yield $\%$ & $M_{\mathrm{n}}(\mathrm{SEC})$ & $M_{\mathrm{w}} / M_{\mathrm{n}}(\mathrm{SEC})$ \\
\hline 1 & MeOK & Ring opening and deprotonation (15/85) & 98.8 & 2400 & 2.18 \\
2 & $\mathrm{MeOK} / 18 \mathrm{C} 6$ & Ring opening and deprotonation (13/87) & 99.5 & 2300 & 1.96 \\
3 & $i$-PrOK & Ring opening and deprotonation (11/89) & 99.3 & 3800 & 2.43 \\
4 & $i$-PrOK/18C6 & Ring opening and deprotonation (8/92) & 98.9 & 3700 & 2.25 \\
5 & $t$-BuOK & Ring opening and deprotonation (5/95) & 99.0 & 7000 & 3.08 \\
6 & $t$-BuOK/18C6 & Ring opening and deprotonation (2/98) & 99.7 & 7200 & 3.38
\end{tabular}

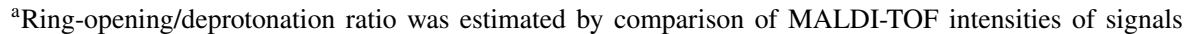
derived from macromolecules and confirmed by ${ }^{13} \mathrm{C}$ NMR data

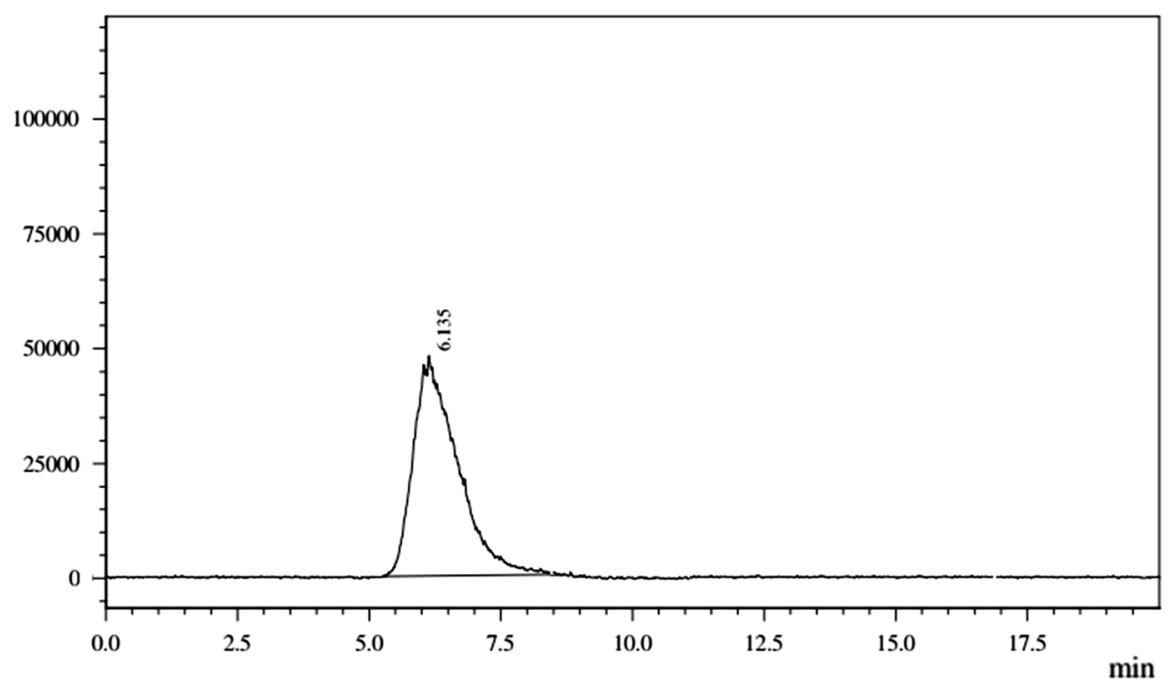

Fig. 5 SEC chromatogram of poly ( $\varepsilon$-CL) obtained with $t$-BuOK and quenched by MeI

mechanism of initiation leads to formation of the same type of macromolecules with the same susceptibility to ionization.

It is worth noting that $M_{\mathrm{n}}$ of the polymers and their dispersities increase, in general, from (1) to (6). It could be consisted with the formation of branched macromolecules, especially in the systems (5) and (6) with highest $M_{\mathrm{w}} / M_{\mathrm{n}}$ values. Exemplary SEC chromatogram of polymer (6) is shown in Fig. 5. 


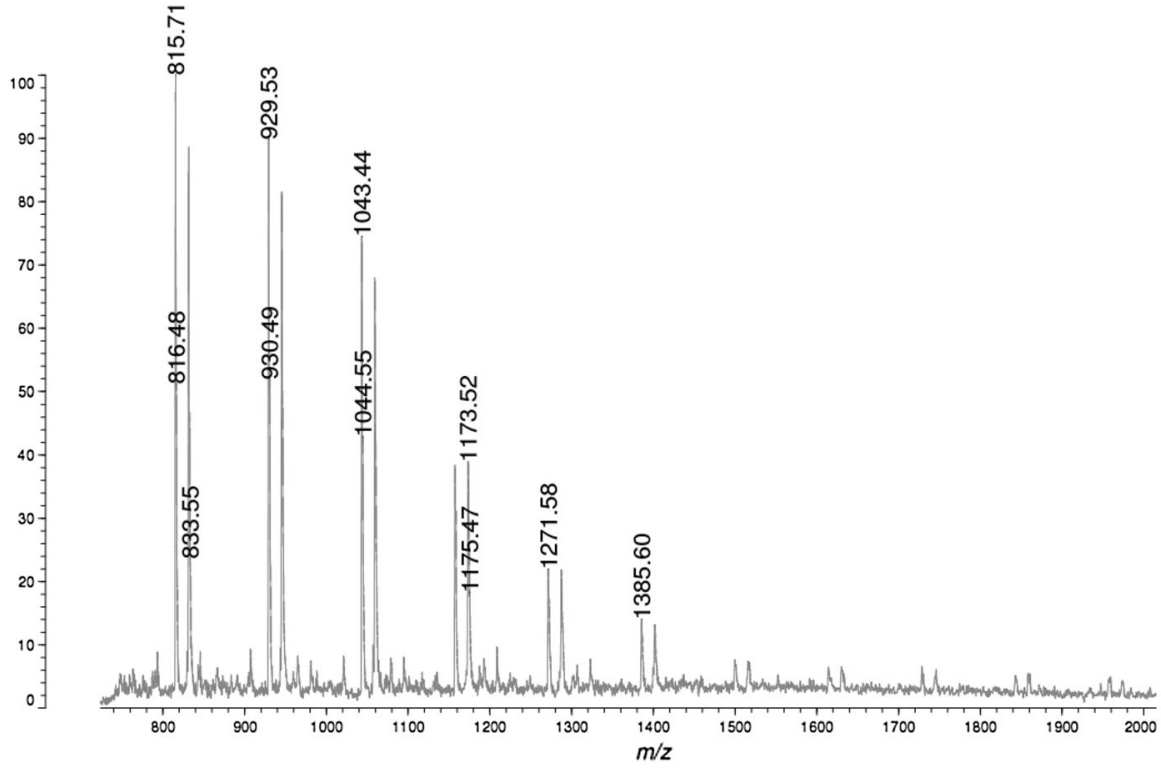

Fig. 6 MALDI-TOF spectrum of poly( $(\varepsilon-\mathrm{CL})$ prepared in the presence of $\mathrm{KH}$ and quenched by MeI

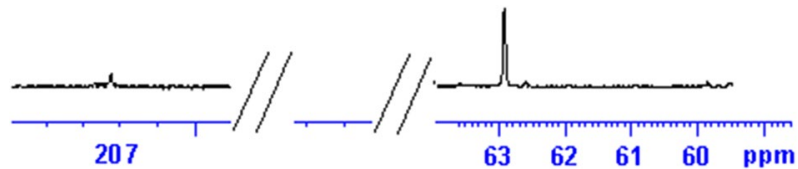

Fig. 7 Carbon signals of $\mathrm{O}=\underline{\mathrm{CH}}-$ starting group and $-\mathrm{OCH}_{3}$ end group in ${ }^{13} \mathrm{C}$ NMR spectrum of poly $(\varepsilon-\mathrm{CL})$ prepared with $\mathrm{KH}$ and quenched by MeI

\section{Polymerization of $\varepsilon$-caprolactone initiated with alkali metal hydrides and other metal salts}

In the next step of the studies, it was observed that polymerization of $\varepsilon$-CL occurs also easily in the presence of KH. During the process no gaseous products were evolved. The reaction mixture was very viscous and almost homogeneous. After quenching with MeI, the polymer obtained was analyzed by MALDI-TOF technique. MALDI-TOF spectrum reveals two series of signals, which indicate the formation of two kinds of macromolecules (Fig. 6).

It was proposed that first series of signals, i.e., from $\mathrm{m} / \mathrm{z} 815.7$ to $\mathrm{m} / \mathrm{z}$ 1385.6, represents macromolecules with aldehyde starting group and methoxy end group. For example, the peaks at $\mathrm{m} / \mathrm{z} 815.7,1043.2$ and 1385.6 represent macromolecules with 7, 9 and 12 monomer units $\left(M_{\text {calc }}=816.0,1044.3\right.$ and 1386.7), respectively. They form adducts with hydrogen ion. ${ }^{13} \mathrm{C}$ NMR analysis of the polymer confirmed the presence of $\mathrm{O}=\underline{\mathrm{CH}}-$ (at $207.21 \mathrm{ppm}$ ) and $-\mathrm{OCH}_{3}$ (at $62.95 \mathrm{ppm}$ ) groups (Fig. 7). 
We suggested that in the first step of the process $\mathrm{KH}$ reacts with the monomer by addition to carbonyl group or direct nucleophilic ring opening in the acyl-oxygen position (Scheme 5) and gives product 5. It becomes the real initiator of the polymerization resulting in macromolecules $\mathbf{E}$ after methylation.

The second series of signals, i.e., from $\mathrm{m} / \mathrm{z} 831.7$ to $\mathrm{m} / \mathrm{z} 1401.6$, represents branched macromolecules with three terminal groups, i.e., one aldehyde group and two methoxy groups. For example, the peaks at $m / z 831.7,1059.3$ and 1401.6 represent macromolecules with 7,9 and 12 monomer units $\left(M_{\text {calc }}=832.0,1060.3\right.$ and 1402.7), respectively. They form adducts with hydrogen ion.

It was proposed that during the polymerization part of macromolecules 6 possessing alkoxide and aldehyde terminal groups react mutually giving macromolecules $\mathbf{F}$ after methylation (Scheme 6).

Similar effect was observed in the polymerization carried out in the presence of crown ethers $12 \mathrm{C} 4$ or $\mathrm{DCH} 24 \mathrm{C} 8$ which form weak complexes with $\mathrm{K}^{+}$counterion. However, after activation of $\mathrm{KH}$ with strong ligands, i.e., 15C5, $18 \mathrm{C} 6$ or C222, MALDI-TOF spectrum of the methylated polymers reveals signals of new macromolecules. No signals of macromolecules $\mathbf{E}$ were found in the spectrum. One series of the signals was already observed in the previous spectrum and represents macromolecules F. However, the second series of signals represents macromolecules formed in other reaction. It was found in separate experiment that during the polymerization hydrogen was evolved from the reaction mixture. We proposed that hydrogen was a product of the monomer deprotonation by $\mathrm{KH}$ activated by strong ligand. Thus, in these systems $\mathrm{KH}$ behaves in the initiation step not only as nucleophile but also as a base. Potassium lactone enolate forms as the product of monomer deprotonation and initiates $\varepsilon$-CL polymerization. The reaction course is similar to that observed for $t$-BuOK (Schemes 2 and 3 ).
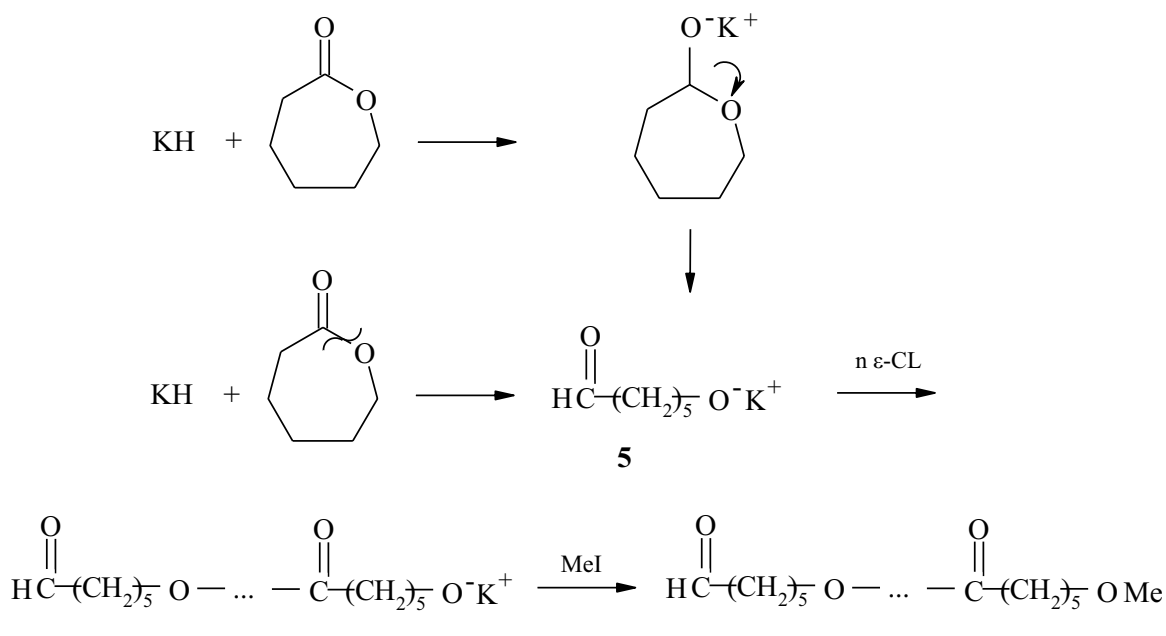
<smiles>CCCOCC(C)=O</smiles>

6

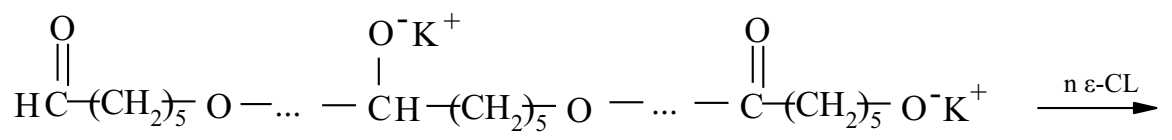<smiles>CCCOCC(C)OCC(=O)CCC(=O)OCC(C)C</smiles>

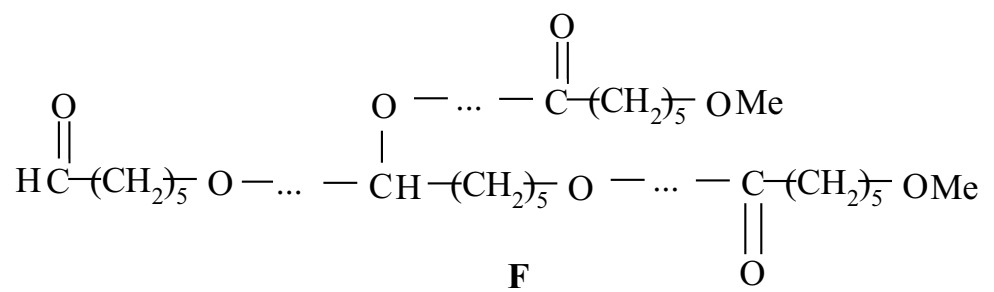

Scheme 6 Formation of branched poly $(\varepsilon-\mathrm{CL})$ in the reaction of macromolecules 6 containing aldehyde starting group and alkoxide end group

It was observed that $\mathrm{NaH}$ without ligand and with $12 \mathrm{C} 4$ or $\mathrm{DCH} 24 \mathrm{C} 8$ does not initiate $\varepsilon$-CL polymerization. However, in the presence of strong ligands, i.e., $15 \mathrm{C} 5,18 \mathrm{C} 6$ or $\mathrm{C} 222$, polymerization occurs easily. In the systems with $15 \mathrm{C} 5$ or $18 \mathrm{C} 6$, initiation takes place exclusively by ring opening of the monomer and macromolecules $\mathbf{A}$ and $\mathbf{B}$ were formed, whereas in the presence of $\mathbf{C} 222$ hydrogen was evolved, which indicated that also deprotonation of the monomer occurred (Table 2).

Molar mass and dispersity of the polymers obtained in the presence of alkali metal hydrides (7-15) were markedly higher in comparison with those prepared with other alkali metal salts (1-6 and 16-19).

Summarizing, alkali metal salts used in this work for $\varepsilon$-CL polymerization react in the initiation step mainly by deprotonation of the monomer as strong bases (5, 6 and 19), as nucleophilic bases $(9,12,13$ and 15) or nucleophilic reagents, which open monomer ring in the acyl-oxygen position $(7,8,10,11,14$ and 16-18). This effect depends on the nature of initiator, i.e., its nucleophilicity/basicity ratio. A broader representation of alkali metal salts like lithium and sodium ones for $\varepsilon$-CL polymerization is planned in the future studies. 
Table 2 Polymerization of $\varepsilon$-CL initiated with alkali metal hydrides and other metal salts activated with various ligands at $20^{\circ} \mathrm{C}$

\begin{tabular}{lllccl}
\hline No. & Initiating system & Mechanism of initiation $^{\mathrm{a}}$ & Yield $\%$ & $M_{\mathrm{n}}(\mathrm{SEC})$ & $M_{\mathrm{w}} / M_{\mathrm{n}}(\mathrm{SEC})$ \\
\hline 7 & $\mathrm{NaH} / 15 \mathrm{C} 5$ & Ring opening & 98.1 & 8900 & 4.37 \\
8 & $\mathrm{NaH} / 18 \mathrm{C} 6$ & Ring opening & 99.5 & 8500 & 3.90 \\
9 & $\mathrm{NaH} / \mathrm{C} 222$ & Ring opening and deprotonation (90/10) & 99.8 & 8400 & 3.71 \\
10 & $\mathrm{KH}$ & Ring opening & 98.3 & 39,800 & 4.65 \\
11 & $\mathrm{KH} / 12 \mathrm{C} 4$ & Ring opening & 98.5 & 8100 & 4.17 \\
12 & $\mathrm{KH} / 15 \mathrm{C} 5$ & Ring opening and deprotonation (88/12) & 99.4 & 8200 & 4.15 \\
13 & $\mathrm{KH} / 18 \mathrm{C} 6$ & Ring opening and deprotonation (70/30) & 99.7 & 7900 & 4.11 \\
14 & $\mathrm{KH} / \mathrm{DCH} 24 \mathrm{C} 8$ & Ring opening & 98.8 & 8000 & 4.12 \\
15 & $\mathrm{KH} / \mathrm{C} 222$ & Ring opening and deprotonation (68/32) & 99.6 & 6000 & 3.16 \\
16 & $\mathrm{Ph}{ }_{2} \mathrm{PK} / 18 \mathrm{C} 6$ & Ring opening & 99.5 & 5400 & 1.21 \\
17 & $\mathrm{Ph}_{3} \mathrm{CK} / 18 \mathrm{C} 6$ & Ring opening & 99.1 & 3300 & 1.19 \\
18 & $\mathrm{Ph}_{3} \mathrm{HBK} / 18 \mathrm{C} 6$ & Ring opening & 99.4 & 3500 & 1.23 \\
19 & $\mathrm{CbK} / 18 \mathrm{C} 6$ & Deprotonation & 99.3 & 9200 & 1.32 \\
\hline
\end{tabular}

${ }^{a}$ Ring-opening/deprotonation ratio for $9,12,13$ and 15 was determined based on volume of hydrogen evolved and analyzed by chromatographic method

\section{Conclusions}

Various alkali metal salts were used for initiation of $\varepsilon$-caprolactone anionic ringopening polymerization in tetrahydrofuran at ambient temperature. In some systems, the initiators were activated by macrocyclic ligands complexing metal cations. In general, the initiators behave as nucleophilic reagents, bases or nucleophilic bases. The most important conclusions to be drawn from the study are as follows:

- Potassium alkoxides, i.e., $\mathrm{MeOK}, i$-PrOK and $t$-BuOK, initiated polymerization mainly by deprotonation of the monomer.

- Nonactivated $\mathrm{NaH}$ was inert, but $\mathrm{NaH}$ activated by $15 \mathrm{C} 5,18 \mathrm{C} 6$ or $\mathrm{C} 222$ initiated polymerization by ring opening.

- Potassium hydride nonactivated or activated by weak ligands as $12 \mathrm{C} 4$ or DCH24C8 reacted by ring opening, but in the presence of strong ligands as $15 \mathrm{C} 5,18 \mathrm{C} 6$ or $\mathrm{C} 222$ initiation occurred by ring opening and monomer deprotonation.

- Other potassium salts activated by $18 \mathrm{C} 6$, i.e., $\mathrm{Ph}_{2} \mathrm{PK}, \mathrm{Ph}_{3} \mathrm{CK}$ and $\mathrm{Ph}_{3} \mathrm{HBK}$, opened lactone ring, whereas $\mathrm{CbK}$ deprotonated monomer.

- Deprotonation of the monomer resulted in macromolecules with lactone starting group, which opened in the reaction with alkoxide end group; it led to the formation of branched polymers.

- Similarly, ring opening by metal hydrides resulted in carbonyl group, which reacted with alkoxide end group forming branched macromolecules.

- Molar masses $\left(M_{\mathrm{n}}\right)$ of the polymers obtained with potassium alkoxides were in the range of 2300-7200 $\left(M_{\mathrm{w}} / M_{\mathrm{n}}=2.18-3.38\right)$; higher $M_{\mathrm{n}}$ had polymers prepared 
with potassium hydrides and other salts, i.e., 7900-9200 $\left(M_{\mathrm{w}} / M_{\mathrm{n}}=3.16-4.37\right)$, especially highly synthesized by the use of $\mathrm{KH}$ without the ligand $\left(M_{\mathrm{n}}=39,800\right.$, $\left.M_{\mathrm{w}} / M_{\mathrm{n}}=4.65\right)$.

\section{Compliance with ethical standards}

Conflict of interest The authors declare that they have no conflict of interest.

Open Access This article is distributed under the terms of the Creative Commons Attribution 4.0 International License (http://creativecommons.org/licenses/by/4.0/), which permits unrestricted use, distribution, and reproduction in any medium, provided you give appropriate credit to the original author(s) and the source, provide a link to the Creative Commons license, and indicate if changes were made.

\section{References}

1. Labet M, Thielemans W (2009) Synthesis of polycaprolactone: a review. Chem Soc Rev 38:34843504. https://doi.org/10.1039/b820162p

2. Lam CXF, Teoh SH, Hutmacher DW (2007) Comparison of the degradation of polycaprolactone and polycaprolactone-( $\beta$-tricalcium phosphate) scaffolds in alkaline medium. Polym Int 56:718728. https://doi.org/10.1002/pi.2195

3. Jenkins MJ, Harrison KL, Silva MMCG, Whitaker MJ, Shakesheff KM, Howdle SM (2006) Characterization of microcellular foams produced from semi-crystalline PCL using supercritical carbon dioxide. Eur Polym J 42:3145-3151. https://doi.org/10.1016/j.eurpolymj.2006.07.022

4. Sinha VR, Bansal K, Kaushik R, Kumria R, Trehan A (2004) Poly-€-caprolactone microspheres and nanospheres: an overview. Int J Pharm 278:1-23. https://doi.org/10.1016/j.ijpharm.2004.01.044

5. Chen DR, Bei JZ, Wang SG (2000) Polycaprolactone microparticles and their biodegradation. Polym Degrad Stab 67:455-459. https://doi.org/10.1016/S0141-3910(99)00145-7

6. Hedric JL, Magbitang T, Connor EF, Glauser T, Volksen W, Hawker CJ, Lee VY, Miller RD (2002) Application of complex macromolecular architectures for advanced microelectronic materials. Chem Eur J 8:3308-3319. https://doi.org/10.1002/1521-3765(20020802)8:15<3308::AID-CHEM3 308>3.0.CO;2-D

7. Ikada Y, Tsuji H (2000) Biodegradable polyesters for medical and ecological applications. Macromol Rapid Commun 21:117-132. https://doi.org/10.1002/(SICI)1521-3927(20000 201) $21: 3<117:: A I D-M A R C 117>3.0 . C O ; 2-X$

8. Khanna A, Sudha Y, Pillai S, Rath S (2008) Molecular modeling studies of poly lactic acid initiation mechanisms. J Mol Model 14:367-374. https://doi.org/10.1007/s00894-008-0278-z

9. Stridsberg KM, Ryner M, Albertsson A-C (2002) Controlled ring-opening polymerization: polymers with designed macromolecular architecture. Adv Polym Sci 157:41-65. https://doi.org/10.1007/3540-45734-8_2

10. Kim MS, Seo KS, Khang G, Lee HB (2005) Ring-opening polymerization of $\varepsilon$-caprolactone by poly(ethylene glycol) by an activated monomer mechanism. Macromol Rapid Commun 26:643648. https://doi.org/10.1002/marc.200400650

11. Woodruff MA, Hutmacher DW (2010) The return of a forgotten polymer-polycaprolactone in the 21st century. Prog Polym Sci 35:1217-1256. https://doi.org/10.1016/j.progpolymsci.2010.04.002

12. Farah AA, Hall N, Morin S, Pietro W-J (2006) Poly(epsilon-caprolactone)-block-polystyrene metallopolymers via sequential ROP and ATRP condition with in situ generated ruthenium catalyst. Polymer 47:4282-4291. https://doi.org/10.1016/j.polymer.2006.03.037

13. Öztürk T, Yavuz M, Göktaş M, Hazer B (2016) One step synthesis of triarm block copolymers by simultaneous transfer radical and ring-opening polymerization. Polym Bull 73:1497-1513. https:// doi.org/10.1007/s00289-015-1558-2 
14. Chu BY, Zhang L, Qu Y, Chen XX, Peng JR, Huang YX, Qian ZY (2016) Synthesis, characterization and drug loading property of monomethoxy-poly(ethylene glycol)-poly( $\varepsilon$-caprolactone)poly(D, L-lactide) (MPEG-PCLA) copolymers. Sci Rep 6:34069. https://doi.org/10.1038/srep34069

15. Öztürk T, Meyvaci E (2017) Synthesis and characterization poly(e-caprolactone-b-ethylene glycolb- $\varepsilon$-caprolactone) ABA type block copolymers via "Click" chemistry and ring-opening polymerization. J Macromol Sci Part A. https://doi.org/10.1080/10601325.2017.1309251

16. Nuyken O, Weidner R (1986) Graft and block copolymers via polymeric azo initiators. Adv Polym Sci 73:145-199. https://doi.org/10.1007/3-540-15786-7_9

17. Öztürk T, Atalar MN, Göktaş M, Hazer B (2013) One step synthesis of block-graft copolymers via simultaneous reversible-addition fragmentation chain transfer and ring-opening polymerization using a novel macroinitiator. J Polym Sci, Part A: Polym Chem 51:2651-2659. https://doi. org/10.1002/pols.26654

18. Penczek S, Cypryk M, Duda A, Kubisa P, Słomkowski S (2007) Living ring-opening polymerizations of heterocyclic monomers. Prog Polym Sci 32:247-282. https://doi.org/10.1016/j.progpolyms ci.2007.01.002

19. Gorrasi G, Pappalardo D, Pellecchia C (2012) Polymerization of $\varepsilon$-caprolactone by sodium hydride: from the synthesis of the polymer samples to their thermal, mechanical and barrier properties. React Funct Polym 72:752-756. https://doi.org/10.1016/j.reactfunctpolym.2012.07.007

20. Grobelny Z, Matlengiewicz M, Skrzeczyna K, Swinarew A, Golba S, Jurek-Suliga J, Michalak M, Swinarew B (2015) Ring-opening polymerization of lactones initiated with metal hydroxide-activated macrocyclic ligands: determination of mechanism and structure of polymers. Int J Polym Anal Charact 20:457-468. https://doi.org/10.1080/1023666X.2015.1036219

21. Hofman A, Słomkowski S, Penczek S (1984) Structure of active centers and mechanism of the anionic polymerization of lactones. Macromol Chem 185:91-101. https://doi.org/10.1002/ macp. 1984.021850110

22. Dale J, Schwartz J-E (1986) Macrocyclic oligolactones by oligomerization of simple lactones. Acta Chem Scand B40:559-565. https://doi.org/10.3891/acta.chem.scand.40b-0559

23. Brown CA (1974) Saline hydrides and superbases in organic reactions. VII. Potassium hydride, highly active new hydride reagent. Reactivity, applications, and techniques in organic and organometallic reactions. J Org Chem 39:3913-3928. https://doi.org/10.1021/jo00940a025

24. Buncel E, Menon B (1976) Metallation of weak hydrocarbon acids by potassium hydride-18crown-6 polyether in tetrahydrofuran and the relative acidity of molecular hydrogen. J Chem Soc, Chem Commun 16:648-649. https://doi.org/10.1039/C39760000648

25. Kricheldorf HR (1988) Poly(lactones). 9. Polymerization mechanism of metal akoxide initiated polymerizations of lactide and various lactones. Macromolecules 21:286-293. https://doi. org/10.1021/ma00180a002 